\title{
Twenty Litres of Tears - the Karen journey from Burma to Ireland
}

\author{
Bridie Kearns \\ Institute of Technology Sligo, Ireland
}

\begin{abstract}
The journey of the Karen community from Burma to Ireland highlights an extraordinary story of survival, courage and the depths of human endurance in the face of adversity. Forced to flee their deeply divided and war- torn homeland, ninety seven Karen people arrived in Ireland in 2007 to begin a new life, only to be faced with the new challenges of adjusting into a modern, western society. This paper wishes to explore their transition and integration experiences on this difficult journey while also highlighting the nature of conflict faced by Karen people in their native Burma.

In order to gain insight into the Karen experience, both primary and secondary research is presented, highlighting common themes around the immigrant perspective.

The findings of this paper reveal the unique lived experiences of these individuals. A violent homeland is depicted with many living in fear of the Burmese army. The participants escape to Refugee camps on the Thai Burma border is referred to, highlighting the difficult choices forced upon these individuals. Their triumph over adversity is discussed in their journey to freedom and a new life in Ireland.

However new challenges are faced in Ireland such as language barriers, education and for some, discrimination. Attempts to face these new challenges are addressed with reference to the support structures available to the Karen in Ireland.
\end{abstract}

\section{Introduction}

The Karen people are the second largest ethnic minority in Burma. The term "Karen" is used to describe twenty groups of Karen-speaking people who hold different religious and cultural values and reside all over South East Asia [1].

In recent times, corruption and oppression are terms which have become synonymous with the country of Burma. The Burmese military have attacked countless Karen villages in an attempt to shift the ethnic balance and force Karen people out of Burma. Forced migration due to this armed conflict led to the arrival of ninety seven Karen people to Mayo in 2007.

This paper will discuss a range of literature which outlines the general experiences of refugees such as forced migration and culture shock as well as living in Refugee camps and the pressures and challenges surrounding transition. This literature is explored as it is significant in its ability to contextualize the story of the Karen community.

\section{Literature Review}

The Refugee Act (1996) draws a distinction between a "regular" refugee and a programme refugee who is referred to in section 24 as "a person to whom leave to enter and remain in the State for temporary protection or resettlement as part of a group of persons has been given by the Government” [2]. Programme refugees are being highlighted due to the fact that the Karen Community hold this status in Ireland at present. The United Nations High Commissioner for Refugees (UNHCR) estimates that there were 9,571 refugees and programme refugees living in Ireland as of January 2010 [3]. The UNHCR in 2009 estimated that only $1 \%$ of the 10.5 million refugees around the world are relocated by the UNHCR to one of the twenty countries who have established resettlement programs [4]. The Office of the Minister of State for Integration in Ireland (2008) states that 929 programme refugees were resettled into Ireland during the period of 2000-2009, 97 of whom are members of the Karen community [5].

In the context of this study, the forced migration of the Karen community from Burma occurred due to armed conflict and gross human rights violations. They were forced to flee their villages, many making the difficult journey to one of the ten Refugee camps on the Thai-Burma border [6].

\subsection{Camp life}

Bowles (1998) describes the camps at as having a village-like atmosphere. The houses are constructed of bamboo and leaf thatch due to the restrictions by the Royal Thai Government (RTG) which prohibits the building of permanent structures. Established in 1997, both Ban Don Yang and Tham Hin Refugee camps were considered temporary shelters and prohibited refugees from building houses. The RTG also forbids refugees to be involved in economic activities however at times this is not enforced and many can find work as labourers in nearby villages. Refugees gather food from the forest to supplement their diet and sell the surplus to earn more money.

Towards the end of the 1990's, many small refugee camps on the Thai-Burma border were 
attacked by the Burmese military and other dissident groups. Therefore, many of these camps were consolidated into much larger camps and the Thai military were deployed to protect the refugees. However this protection meant the erection of large fences around the camps and restricted movement of persons in and out. This impacted on the Refugees livelihoods and autonomy, making them more dependent on the Non Governmental Organisations (NGOs) [7].

\subsection{Resettlement}

From these camps, the United Nations have intervened in the past number of years to resettle the refugees to safe countries. They are then considered programme refugees [4]. These countries include USA, Canada, Australia, much of Scandinavia and on a smaller scale, Ireland, who accept up to two hundred programmed refugees annually on referral from the UNHCR [4]. Ninety seven members of the Karen community arrived in Ireland as programme refugees in 2007 as part of the resettlement programme and settled in two locations in Mayo, Ballina and Castlebar [8]. So one may then question, how moving to a new society can impact this community as a whole?

\subsection{Cultural Shock}

Research in other contexts show that the unfamiliarity of the new society may cause "culture shock" which is a term coined by Kalvero Oberg in1960 to describe the anxiety felt by not knowing what to do in a new culture [9]. It is the initial period of adjustment to an unfamiliar environment where one does not know what to expect or what is expected of them. Pedersen (1995) suggests a number of components to culture shock which include; the familiar social cues which dictate behaviour are different or absent in the new society, values of a person may not be respected, disorientation of culture shock causes anxiety, hostility or depression or finally, the person feeling that initial culture shock is permanent [9].

Instances of Culture shock are also evident in research carried out with the African community in Ireland. Mutwarasibo (2002) discusses culture shock highlighting its effect on the integration process. He identifies two factors which are central to integration, language acquisition and links with members of the host culture. He states that these factors can often be affected by culture shock and feelings of isolation which are prevalent in the African community due to culturally unfamiliar surroundings and feelings of abandonment of their culture of origin [10].

\subsection{Transitional experiences}

The transition into a new culture may also cause a dilemma about culture versus integration. Ward, Bochner \& Furnham propose that despite the principles of integration in a host country, immigrants are expected to "assimilate to the dominant ethos, at least at the overt behavioural level...they are expected to learn the culture of their hosts" [11]. This invariably presents two options; to conform to the dominant society, whereby weakening the ties they may have to their country of origin or alternatively, to reject aspects of the new society, which may cause social and economical exclusion. In an attempt to resolve this problem, many migrants become members of two distinct social networks, co-national migrants and host culture individuals [11].

These integration transitions can be even more challenging for children in Refugee groups. Eisenbruch (1988) investigates the emotional impact of transitions on Refugee children, in particular Indochinese children who re-settled in the USA. He states that it is important to regard refugee communities as a social group who experience a collective sense of grief after the apparent loss of their cultural identity. He asserts that refugee children are the most vulnerable and susceptible to developmental disruption. He suggests that grief, whether it is a loved one or a culture, can impact on an individual's physical and mental well-being. There is also the added pressure and strain of young children becoming translators for their parents when they begin to learn a new language in their settled country [12]. Specifically, Edwards (2002) discusses refugee children in the UK becoming advocates for parents due to the better command of the language they have gained through schooling: this essentially meant that the children accompanied their parent's to a range of places such as hospitals or doctors offices to translate the new language [13].

\section{Methodology}

As the focus of the study rests on the lives of the Karen people, an interpretive paradigm was chosen in the form of in-depth interviews. The interview process is a more flexible approach and as Mason describes, the "interactive, situational and generative" nature of a qualitative interview, it can be considered more suited to this type of study than "the more structured composition and uniform style of a survey interview” [14]. Houser's (1998) 
discussion of the flexibility of interpretive research in the exploration of the exceptional experiences of individuals such as those experienced by the Karen community lends strong support to the application of this paradigm as it is these key experiences that are under investigation [15]. For example, the researcher may be flexible in the use of open-ended questions and request the participant to expand on key areas of interest.

Participants were chosen in order to conduct narrative research using the purposive/representative method. This sampling method appeared to best suit this particular study. The participants were chosen because of their high level of fluency and pronunciation of the English language which reduced the possibility of misinterpreting their story. Both genders participated in the study from a range of ages to address possible gender or generational differences.

\subsection{Data Analysis}

Goodley, Lawthom, Clough \& Moore identify four methods of narrative data analysis; discourse analysis, voice relational analysis, grounded theory and literary analysis. The data collected was analysed using grounded theory as it was deemed fit for the purpose that is intended [16].

Glaser and Strauss, who originally formulated the idea of grounded theory, propose three stages or levels in what they call the constant comparison method of analysing data. These are as follows;

Comparing incidents in the data which can be assigned to a category: This is achieved by coding words and incidents in the data, creating categories and placing codes in these existing categories.

Integrating categories and discovering the properties of that category: Memos are used to discover what the properties of each category are. Then categories are merged to become a solid category which covers many codes.

Delimiting the emerging theory: This is in essence the collapsing of categories to reveal the emerging theme [17].

In practice, these three stages were applied to the study by reviewing the transcripts of the interview process, noting key words and phrases and placing them into categories. From these categories, prevailing themes emerged as discussed below.

\subsection{Limitations of the study}

Every study encounters limitations as does this research. To improve the quality of the research and reduce the possibility of research bias, the principles of trustworthiness were applied to the study. Lincoln and Guba’s framework (1985) suggest 4 criteria for trustworthiness in qualitative inquiry: credibility, dependability, confirmability and transferability [18].

To promote credibility the researcher adhered to a code of ethics, considered legal obligations, provided an informed consent form and documented the participant's story verbatim. In the case of dependability, it is the methods and not the findings that may be replicated. To ensure confirmability, the data collected reflected "the participant's voice and not the biases, motivations or perspectives of the researcher" while questions were designed from the review of literature and not from personal opinion [18]. The interviews were transcribed verbatim to ensure the participants own words formed the basis of this research. Finally in the case of transferability, as in dependability, it is fair to assume that any researcher could adopt these methods and apply them in a similar context

\section{Findings}

The findings of this study are significant as they offer direct knowledge of the Karen community, which in turn offers key perspectives on other immigrant communities who reside in Ireland at present. The findings provide snapshots of the lives of the participants documenting their time in Burma, their escape to Refugee Camps, their journey to Ireland and their experiences of living here, including engagement with Irish culture. Participants are referred to as Paw Ta Su, Saw Thoo and Naw Eh Wah.

\subsection{A violent homeland}

The Karen Human Rights Group (2000) describe this devastating situation in Burma at the beginning of the last decade. They describe a country in turmoil in the hands of a vicious government and many militant rebel groups. They refer to the Burmese Army as a "death squad” who destroy Karen villages and force the Karen to flee into the hills for refuge. They assert that the simple act of meeting the Burmese army is a death sentence for many as they are known to shoot villagers on sight [19].

The participants confirmed this depiction, portraying the Burmese military as vicious and immoral individuals whose sole purpose was to rid Burma of the Karen ethnic group. They spoke of the destruction which took place in their villages and of long periods of time spent hiding in the hills in an attempt to protect their young families. Paw Ta Su describes how the Army killed indiscriminately, young or old "boy or girl... they kill." They describe a constant fight for survival at the heart of a bloody 
war between the Karen National Union (KNU) who are attempting to protect the Karen people and the Burmese Military who are trying to kill them because of their ethnicity.

Saw Thoo refers to this when he says "Burmese army came to my village... every home in my village, the school, the Nursery school, they put on fire every home, every school they put on fire... that's (why) we have to leave." Paw Ta Su re-enforces this view of a vicious militia when she tells of 31 villagers she knew who were killed in the forest while trying to escape.

Paw Ta Su describes her escape to the forest when the army came to her village. She describes hiding with her young children in the forest and being unable to sleep because of wild animals coming close to her and her children. She tells of her fear as the Burmese Army approached her hiding place; "I think I will die with my daughter because military come very close...my husband not to see me, my parents...my sister also... I will die, just me and my daughter." She recalls her sadness due to the fact she was separated from her family for one year; "I stay with my tears for a year, I will keep together maybe twenty litres of tears when I think of my husband far away.”

\subsection{New beginnings: journey to a new life}

It is to be expected then, that the transition from a culture of fear, oppression and survival, to living in Ireland, a democratic and peaceful country will have an enormous impact on the community. Coming to Ireland marked a new beginning for these individuals. Having had no prior knowledge of Ireland, the journey to Ireland marked their embarking on an even bigger journey into an unknown culture.

Participants recall the happiness they felt when they were told they were leaving Ban Don Yang Camp. For Naw Eh Wah it was the chance to further her education in the hopes of becoming a nurse while Saw Thoo considered it the best thing for the children in the community. Paw Ta Su remembers feeling happy and hopeful that she would find nice friends in Ireland. "I pray that when I arrive in Ireland, maybe I will meet new friends and good friends for me, not bad like the Burmese military...All the bad things I will forget.. everything, I will grow a new life in Ireland.”

However the study also uncovered difficulties the Karen faced upon their arrival in Ireland. Pedersen (1995) refers to culture shock which can occur when a group of people are introduced into a new culture which is different to their own [12]. The participants mention a number of major differences between Ireland and Burma which contributed to what they acknowledge as culture shock upon arrival to Ireland. They identified changes in diet, education, language and missing their homeland as contributors to an overall feeling of Cultural distress.

Pedersen (1995) also describes a number of emotional affects of the disorientation of culture shock which include anxiety, hostility or depression [12]. This was alluded to by Paw Ta Su when she speaks of sadness in the community because of difficulties in finding employment due to lack of experience and differences in technology. She states: "Here, they feel sad because to find job is very difficult, because they would like to work, the working experience we don't have...in Burma, we working with hands and with body and here with machine and with brain.”

4.2.1. Language \& Food. Paw $\mathrm{Ta} \mathrm{Su}$ describes language as difficult because "some people can't read cant write." She tells of some people in the community who copy the homework of their small children, for example their alphabet. "They keep practicing to write their name, address because very difficult for to them." She states that people with better English in the community such as her eldest daughter often help others. Naw Eh Wah describes that when they first arrived, as one of the only people to have any English, she became the translator for the community. She embraced this role saying "I do like doing this job, if I can speak a little bit I will help. If I can do anything yeah, I will help.”

Paw Ta Su describes the confusion felt by the community about the diet in Ireland. She describes difficulty during shopping trips for many in the community as they are unable to read food labels. Paw Ta Su laughs as she recalls one person making coffee with black pepper and salt on an outing to Pontoon, "he thought this ones black so it is coffee, this ones white, its sugar." The community now shop in "The Africa Shop" which provides food from Thailand, India etc, similar to Karen food.

4.2.2. Home Sickness. Naw Eh Wah says that some of the older members of the community are struggling because they have difficulty remembering their addresses and phone numbers and "sometimes they feel sad and miss home." Naw Eh Wah admits she misses her uncle who lives in a refugee camp and hopes to visit him someday. Paw Ta Su supports Naw Eh Wah's description of homesickness by describing a man in the community who cried every day when he arrived. "He not happy, he miss Burma. It's cold here and he miss his daughter in refugee camp." Paw Ta Su comforted and told him “Don't be 
crying because one day you will visit to your daughter."

4.2.3. Education. Paw $\mathrm{Ta} \mathrm{Su}$ believes that the education system is the most difficult thing facing Karen children of school-going age. The language is difficult for them and the level is much higher than what they studied in the camp: "They can't follow because they are not really good about the English language." Saw Thoo states that he encourages his children to learn English and does not mix the Karen language because he does not want to confuse the children. He states he will teach them more about Karen culture when they are older.

\subsection{Transitions and children}

Eisenbruch's (1988) work with Indo-Chinese children who settled in the USA revealed a sense of grief among the immigrants due to the apparent loss of Cultural identity [15]. While this does not seem evident in the case of the Karen community, his discussion of the pressure on young people in resettled communities to become translators resonates in the case of Naw Eh Wah who became translator for the community at a very young age. Younger children translating for their parents was alluded to by $\mathrm{Paw} \mathrm{Ta} \mathrm{Su}$ when she discusses an individual having difficulty reading food labels in the shop and having to ask his child to help. There were many instances of this when the community arrived; adults who had little or no English language had to rely on the language abilities of children who were learning English in school. Eisenbruch (1988) describes the pressure of being a translator for parents or older siblings as an emotional impact of transition for a child [15].

\subsection{Support and integration: Irish connections}

The participants identify significant support systems they have availed of since their arrival in 2007. Upon arrival, the community was brought to a reception centre in Ballyhaunis, Co Mayo where they spent 10 weeks learning about different aspects of Irish life and culture. Paw $\mathrm{Ta} \mathrm{Su}$ discusses the support which she has received to improve her language skills. She states that the Karen Befriending Group helps the community and that every Tuesday; she attends conversation class at the Family Resource centre in Castlebar. Of this she says she is "so happy we have a conversation group because when we meet there, they like to help us about everything we have a problem with.” Saw Thoo also notes that a number of the community attended an English course when they arrived initially. He also attends a drumming class and is a member of the community garden where he meets many Irish friends.

Saw Thoo speaks in-depth of his Irish connections and opportunities for practicing English and meeting people. He argues that if he was to stay within the community and only speak Karen, it would not have a positive outcome for him; "We have to go around the town, we say hello to somebody, somebody will know our face... that's the way we get the better English." He comments that he has many Irish friends and of this he says "The friend is very important to meet."

Many of these support structures are now on a voluntary basis and include weekly English conversation classes, English courses, and outings planned by the Karen Befriending group in Castlebar.

\subsection{A balance of two cultures}

Ward, Bochner \& Furnham (2001) propose two options for immigrants in the process of transition into a host country; to conform to the dominant society or to reject aspects of that society in order to protect their culture [14]. To examine which path the Karen community may have chosen, the participants were questioned about practicing their own traditions in Ireland and to what extent they engage in Irish traditions. All of the participants express a strong desire to keep their traditions safe here in Ireland. Paw Ta Su argues that nothing has changed "we keep safe our culture." They celebrate their special Karen days such as Karen New Year and Matura (Martyr) Day, while wearing their Traditional dress.

However Saw Thoo and Naw Eh Wah note subtle changes in their culture. Naw Eh Wah talks of the change from bamboo bed to mattress, sitting crossed legged on the floor to sitting on couches and chairs, from sarong to trousers and changing cooking methods from open fire to electric cooker.

Paw Ta Su brings to light the level of engagement with Irish traditions in the community when she describes a friend who is learning Irish dancing and her own passion for the Irish legend "The Children of Lir". Similar to Paw Ta Su, Saw Thoo describes the involvement of his family in the St Patrick's Day festival: "We celebrate every year...We wear the green, we wear the hat. The children get the flower (shamrock) on their face, we wear our traditional clothes." He also describes his involvement on an Irish farm, helping his friends tend to the turf on the bog. What is worthy of note is 
the level to which the community attempt to adopt Irish culture while still maintaining their own. It appears that the community has chosen to reject neither culture. This finding clearly contradicts Ward et al's (2001) claim that immigrants choose one path, to conform or to reject the new society as they strive to immerse themselves in Irish culture while still keeping safe their traditions, dress, and language.

Furthermore, the argument of two distinct social networks, co-national migrants and host culture individuals is clearly seen in the case of the Karen community in their discussion of Irish friends and the close nature of the community [14]. It is evident that this group of people endeavour at every opportunity to make Irish friends and integrate themselves into the local community.

\subsection{Barriers to integration}

The review of literature identified discrimination and racism significant barriers to integration. The 2008 Shadow Report on Racism in Ireland confirmed a strong presence across a number of sectors [20]. On a positive note, none of the participants spoke of personal incidents in which they felt discriminated against. However Paw Ta Su spoke of problems experienced by a friend in the community. She recalls people shouting at them and saying "Burmese people not very nice people, very bad people.” Paw Ta Su told her friend that she should not worry about this because "We are Karen, we are not Burmese." She also states that a number of people have confused them with Chinese people and made derogatory remarks. However she expresses that these are isolated incidents and that the Irish people they have encountered have been very welcoming of the community.

\section{Conclusion}

This paper has examined the transition and integration experiences of the Karen Community from their homeland of Burma to their new life in County Mayo. Relevant literature was presented surrounding some general refugee experiences when integrating into unknown cultures such as Culture Shock. Experiences surrounding the resettlement process and camp life were also discussed underlining the experiences of various ethnic groups, for example the African community in Ireland and the Indo-Chinese in the USA. Furthermore the literature introduced the Karen ethnic group and highlighted their struggle in a turbulent and oppressive homeland. Their journey to Ireland was outlined under their "programme refugee" status.
The methodological paradigm which was employed to conduct research was interpretive, namely in-depth semi-structured interviews. Data was then analysed using a narrative analysis method, grounded theory. Limitations to the study were addressed which integrated Lincoln and Guba's framework of trustworthiness into the study.

The study revealed findings which supported, contradicted and contributed to the existing knowledge of the transition and integration experiences of immigrant communities, in particular the Karen community. The primary findings suggest a number of difficulties encountered in the areas of language, food, education and feelings of homesickness upon arrival in Ireland. All participants testified to sufficient support structures and their outstanding attempts to adapt and integrate into Irish society were noted. Their ability to immerse themselves in Irish Culture while remaining true to their cultural heritage highlighted a contradiction in the current literature available.

\section{References}

[1] Thawnghmung. A. M (2008) The Karen revolution in Burma: diverse voices, uncertain ends, Washington, East West centre.

[2] Irish Statute Book (1996) 'Refugee Act 1996,' http://www.irishstatutebook.ie (03 December 2010).

[3] United Nations High Commissioner of Refugees (2010) '2010 Regional Operations Profile - Northern, Western and Southern Europe,' http://www.unhcr.org (20 $20^{\text {th }}$ November 2010).

[4] United Nations High Commissioner for Refugees (2009)‘Resettlement,'http://www.unhcr.ie/resettlement.ht ml (04 December 2010).

[5] Office of the Minister of State for Integration (2008) 'Resettlement of Programme Refugees - 2000-2009,' http://www.integration.ie (10th December 2010).

[6] Skidmore. M. \& Wilson. T. (2007) Myanmar: the state, community and the environment, Australia, ANU E Press.

[7] Bowles, E. (1998) 'From village to camp: Refugee camp life in transition on the Thailand Burma Border,' Forced Migration Review, (2), pp. 11-14.

[8] Mulherin. G. (2009) 'The Karen in Ireland,' http://www.karenireland.com (12 December 2010).

[9] Pedersen. P. (1995) The five stages of culture shock: critical incidents around the world, Connecticut, Greenwood press. 
[10] Mutwarasibo, F. (2002) 'African Communities in Ireland,' Studies: an Irish Quarterly Review, (91), pp. 348358.

[11] Ward. C. A., Bochner. S. \& Furnham A. (2001) The psychology of culture shock, $2^{\text {nd }}$ edn, Taylor and Francis eLibrary; http://books.google.ie (25 November 2010].

[12] Eisenbruch, M. (1988) 'The Mental Health of Refugee Children and Their Cultural Development,' International Migration Review, (22) (2), pp. 282-300.

[13] Edwards, R. (ed.) (2002) Children, home, and school: regulation, autonomy or connection? Taylor and Francis eLibrary; http://books.google.ie (8th January 2011].

[14] Mason, J. (2002) 'Qualitative Interviewing: Asking, listening and interpreting,' May, T. ed. Qualitative research in Action, London, Sage, pp. 225-242.

[15] Houser, R. (1998) Counseling and educational research: evaluation and application, California, Sage.

[16] Goodley, D., Lawthom, R., Clough, P \& Moore, M. (2004) Researching Life Stories: Method, theory and analyses in a biographical age, London, Routledge Falmer.

[17] Glaser, B.G. \& Strauss, A.L. (1999) The Discovery of Grounded Theory: strategies for qualitative research, New York, Aldine de Gruyter.

[18] Polit. D. F \& Tatano Beck. C. (2008) Nursing research: generating and assessing evidence for nursing practice, $8^{\text {th }}$ edition, Philadelphia, Lippincott, Williams \& Wilkins.

[19] Karen Human Rights Group (2000) Suffering in Silence: The Human Rights Nightmare of the Karen People of Burma, Parkland, Universal publishers.

[20] Lynch, C. (2008) 'The European Network against Racism shadow report 2008: Racism in Ireland,' http://www.cms.horus.be (13 ${ }^{\text {th }}$ December 2010]. 